\title{
LYING TO PATIENTS: ETHICAL DILEMMAS OF COMMUNICATION IN PAEDIATRIC PRACTICE
}

\author{
Mudiyanse R.M. \\ Department of Paediatrics, University of Peradeniya, Sri Lanka
}

\begin{abstract}
$\mathrm{D}$ octors resort to conceal information or even to give partially wrong information with the intention of safeguarding patient's benefit. This stand is not acceptable for medical ethicists. However not divulging the entire truth has been seemingly beneficial in three case scenarios presented in this paper. Three case scenarios involve avoiding investigating a possible paternity dispute, giving false information to pursue on a low cost drug regimen, and not promoting legal action against serious therapeutic misadventure. These case scenarios were evaluated based on the definition of deception in Buddhist teaching. Accordingly, lack of intention to harm and lack of harm caused by the deception allow room for an argument that non-disclosure or partially incorrect disclosure is not a sin and therefore acceptable. However accepting lack of harm or even the benefit as an excuse for deception as a policy in a wider context of clinical practice needs careful consideration.
\end{abstract}

\section{INTRODUCTION}

Doctors have the privilege of entering the inner worlds of people and gathering information pertaining to the medical problems that they have been consulted, irrespective of whether such is related or unrelated to the malady of the patient. This information is gathered by verbal communication or investigations. The knowledge and experiences that they have embraced demands them to engage constantly in scientific interpretation of the information received. Information available to doctors is not always essentially beneficial to the patient, family and society. In fact they can be beneficial to some but not to others and sometimes may not be beneficial to everybody. In such situations, doctors have to face the dilemma of deciding what to and what not to divulge. Finally, this raises the question of whether doctors have to tell the truth and nothing but the truth.

In this recollection of three case histories the author shares his personal experiences of lying in different situations.

\section{$\underline{\text { Case - 01 }}$}

Baby K (2 years) was diagnosed as beta thalassemia major at the age of 8 months. Having confirmed the diagnosis by HPLC, a life long journey of regular blood transfusions was commenced. The child was brought to the ward once a month and given a blood transfusion to maintain his haemoglobin level at $9.5 \mathrm{~g} / \mathrm{dl}$. Both parents who were initially distressed had gradually adapted to the routine of coming to the hospital for blood transfusions. The mother is a housewife educated up to Advanced Level and the father is a technical officer working in Colombo.

The case was discussed during the routine ward round conducted by a team consist of a consultant, registrar, senior house officer, intern house officer, fourteen final year medical students and a nurse. The registrar took the lead role in presenting cases.

The diagnosis of baby $\mathrm{K}$ was confirmed as beta thalassemia major at the age of nine 
months. Since then regular blood transfusion has been commenced. After the $10^{\text {th }}$ transfusion he will have to take one tablet of Deferasirox daily to remove already accumulated iron from the body and he will have to continue this treatment forever in his life. So far there had been no problem with the management of this patient with regards to compliance or side effects. However, in this case the father has not been a thalassemia carrier and that raised a concern regarding the diagnosis as in case of a child with thalassemia major both parents should invariably be thalassemia carriers. Only exception would be a situation of a new mutation. The discussion in the ward round led to consideration of genetic testing to evaluate for genetic mutations in the child and repeating blood tests regarding father's thalassemia status. At this stage the group started making comments about DNA testing for paternity as one of the option in the process of evaluation.

At this stage the author curtailed the theoretically rational discussion and inquired about blood transfusion and other aspects of care to the child ignoring all the suggestion for further evaluation.

\section{$\underline{\text { Case }-02}$}

Miss B (10 years) was brought to the outpatient clinic room by her father and mother. The father had to carry this quadriplegic bed ridden child with cerebral palsy who is obviously too heavy for the mother to carry. Father sat on the small chair in front of me with the child on his lap, glancing at my face asking, "Do you remember me" The mother kept the medical records in front of me. I could not remember them. I pretended to remember, returned a smile and started turning pages in the record book.

According to the records, the child has survived an episode of encephalitis but was left with severe quadriplegia at the age of 3 years. After the initial care they moved to another city and consulted a number of specialists and a diagnosis of Lennox Gastaut syndrome was established. She has been on four antiepileptic drugs (Vigabatrin, Clonazepam, Clobazam, Topiramate) for the past 5 years. I was impressed by the comprehensive care that had been offered to this child. After reading the book, I was holding the hands of the baby and while stroking the head asked from the parents what the author can do to help.

The mother explained her difficulties. Spending more than $35,000 /=$ per month has not been an easy task. However, in spite the expensive treatment the child seems to be getting frequent convulsions. Therefore, the mother requested giving the same drug that was given to the child at the onset of the illness.

I noticed that we had used phenytoin immediately after encephalitis and continued the same for about two years. Subsequently phenytoin had been stopped and newer and more effective drugs had been initiated. At this stage options left were to start phenytoin sodium or to redirect the mother to neurologists with a referral letter explaining mother's concerns.

The author decided to use phenytoin sodium without further consultations and explained possible risks and adverse effects. Mother was not worried about the possibilities of the failure in the treatment but express major concerns when the well-known complications of phenytoin such as gum hypertrophy, excess growth of hair and facial disfiguration was discussed. Mother expressed reluctance to start phenytoin. However at this stage the author continued explaining possible advantages of starting phenytoin and how those advantages could overweigh the adverse outcomes like facial disfiguration and finally managed to convince the mother on the trail of using phenytoin sodium. 
$\underline{\text { Case }-03}$

This case is about a prematurely born (34 week) low birth weight (1800 g) baby in a special baby care unit. On the $10^{\text {th }}$ day of life a nurse had severed the $5^{\text {th }}$ finger of this tiny baby's left hand by accident. When the author arrived at the ward the nurse was visibly emotionally distressed. Emergency care has been provided.

The author planned to break this bad news carefully. Communication skills with regards to arranging the environment, building rapport and exploring the parent's perceptions were followed by the actual breaking news. The reaction as expected was overwhelming and a little short of being physical. My silence and acceptance of their emotions were good enough to manage the situation. This episode was followed up with several discussions with parents and their relatives. The possibilities of legal action were discussed. I disclosed the possible mechanism of getting hospital records and more importantly the fact that the care for the child will not be affected as a result of legal action. However after much contemplation they did not proceed to a legal battle.

\section{DISCUSSION}

Doctors are supposed to "tell the truth and nothing but the truth". The American Medical Association's Principles of Medical Ethics take a step further and states that not only will a physician 'be honest in all professional interactions' but also promote reporting of physicians engaging in deception to the appropriate entities ${ }^{1}$.

All three case scenarios demonstrate varying degrees of lying and breach of professional conduct.

\section{$\underline{\text { Case }-01}$}

The consultant is trying to hide the paternity issue and cover it up with possibilities of genetic mutation, sacrificing the truth for the harmony of the family that will be crucial for the child's life. However what about the father's right to know, and the child's right to know?

\section{$\underline{\text { Case }-02}$}

The consultant was lying to the patient regarding side effects of phenytoin and violating the code of professional conduct by not communicating with a colleague who had been looking after this child. Reflecting on the situation, I feel that I did not want any obstacle to my idea of trying phenytoin on this child entirely because of the presumed benefits that would accrue to the child according to my perception.

\section{Case-03}

Severing of a body part is a grievous injury according to panel cord that warrants major punishment. However this case ended up in a departmental inquiry resulting in warning and transfer of the nursing officer to another unit. However I am not sure whether I had done the justice by settling emotions of the parents after the little finger of their little boy was severed. Here I never lied as far as facts are concerned. I never discouraged legal action. Probably I developed genuine relationships and harnessed empathy towards the nurse. Do I have a duty to encourage and promote legal actions in a case like this? I have divulged correct facts, but have communicated correct emotions and correct moral values that are essential components of communication. According to the directive of the American Medical Association there is duty to promote reporting such cases.

Lying is considered a sin in almost all religions. It is the forth out of the five precepts in Buddhism. According to Theravada Buddhism violation of fourth precept constitutes four elements. Firstly there should be a situation to lie about, secondly there should be an intention to deceive, and thirdly there should be an expression of false information by words, gestures or body language. Finally 
conveying a false impression should be completed $^{2,3,4}$. This definition highlights that there should be an intention to deceive. I was trying to find relief in this definition as I did not have intention to deceive. I am sure the readers have the right to ask the question. Are you sure?

Concealment of information for the therapeutic advantage on the basis of the Hippocratic dictum "primum non nocere" (first do no harm) has been challenged as a valid excuse. In fact some courts have rejected this argument ${ }^{5}$. Patients autonomy and obligation of loyalty demand truth telling. Patient contract with the doctor would be breached leading to mistrust if the doctor fails to provide all relevant information to the patient. Patients know how to manage information available to them ${ }^{5}$.

The second case deals with providing palliative care. Providing palliative care for children with incurable disease should have a multidisciplinary approach to relieve pain and symptoms while attending to emotional and spiritual needs of the child as well as the family. This should be appropriate to the society and the culture with the involvement of the primary care doctor ${ }^{6}$. Taking over patient care on the patient's request is not an unusual practice in our country. This is commonly happening during the private practice rather than the hospital practice. However this patient requested to take over the care in the hospital clinic. Whether acceptance of a patient without a referral deserves to consider as a breach of professional conduct is dubious. Offering a drug like phenytoin that has been given up due to known side effects like severe gum hypertrophy could be considered as deceiving the patient, specially when the side effects were only partially revealed. The only excuse is probably the benefit of the family.

The honesty although desirable may not be the best always. The duty to tell the truth is not absolute and can be balanced against the advantages and disadvantages. In fact the doctors have no duty to disclose all the information unless it is relevant ${ }^{7}$. The blood tests done in the first case was not done with the intention of testing paternity. Therefore doctors have no duty to disclose ${ }^{7}$. As the purpose of the test ${ }^{7}$ was not testing paternity in fact it will be unethical to divulge this information without consent ${ }^{7}$. However Zen Buddhist teacher Reb Anderson suggests that we distinguish between what is harmful and what is hurtful. "Sometimes people tell you the truth and it hurts a lot, but it is very helpful," ${ }^{3}$ GMC elaborates the need for being honest and truthful always 8 .

\section{CONCLUSIONS}

The prime need of being respectful and supportive to our patients is essential. To what extent we should strictly adhere to total disclosure of information should be decided base on the circumstances of the case. The Buddhist disclosure on right speech (sammavacha) proposes the following criteria for deciding what is worth saying; is what is disclosed factually true, is it the correct time to divulge, is the receiver ready to listen and is the message beneficial and delivered in a calm manner. I consider this is a worthy guide for doctors. 


\section{REFERENCE}

1. Sokol D. Can deceiving patients be morally acceptable? BMJ. 2007 May 12; 334(7601) 984-988.

2. http://buddhism.about.com/od/thetripita ka/a/tripitakahistor.htm

3. Anderson $\mathrm{R}$ Being Upright: Zen Meditation and the Bodhisattva Precepts (Rodmell Press, 2001) Berkeley, California.

4. "AbhayaSutta: To Prince Abhaya" (MN 58), translated from the Pali by ThanissaroBhikkhu. Access to Insight (Legacy Edition), 30 November 2013,http://www.accesstoinsight.org/tipi taka/mn/mn.058.than.html
5. Edwin AK, Don't lie but don'ttell the whole truth: the therapeutic privilege- is it ever justified? Ghana Medical Journal. 2008:42.4. 156-161.

6. Himelstein BP, Hilden JM, Boldt AM, Weissman D. Pediatric Palliative Care. NEJM. 2004;350:1752-62.

7. Sokol D. Truth-telling in the doctor patient relationship; a case analysis. Clinical ethics 2006;1:3. 000-100.

8. General Medical Council. Duties of a doctor registered with the GMC www.gmc-uk.org/guidance/archive /library/duties_of_a_doctor.asp. [PubMed] 